\title{
Noni (Morinda citrifolia)
}

\author{
Naylene Carvalho Sales da Silva \\ Centro de Ciências Agrárias, Universidade Federal do Piauí, Campus do Socopo, Teresina - PI - Brasil, \\ CEP: 64.049-550 (naylenecarvalho@yahoo.com.br)
}

\section{Objetivo}

Pesquisar o grau de utilização aplicado ao Noni e apontar o foco da maior aplicação de patentes.

\section{Aspectos tecnológicos}

O NONI (Morinda citrifolia) foi descoberto na Polinésia Francesa e Havaí. É o extrato de uma planta utilizada no combate aos efeitos do envelhecimento, desde as dores mais simples, insônias e falta de energia, até mesmo a diabetes, pressão alta e artrite. Foram observados grandes benefícios nos sistemas cardiovascular, ósseo, nervoso, imunológico, respiratório, endócrino, muscular, cutâneo, e na degradação progressiva dos tecidos. Este fruto nutricêutico milenar originário da Polinésia Francêsa (Asia) tem sido uma fonte de saúde e bem estar, propagou-se pela a América Central e América do Sul, e há dois anos foi introduzida no estado do Piauí. Sua riqueza nutricêutica tem inspirado pesquisadores nas áreas de medicina complementar e alternativa (CAM), humana e animal. A medicina complementar e alternativa é uma ampla categoria de produtos e de esforços que são unidos em sua justaposição à medicina alopática convencional (Fontana rosa 2000; Jonas e Levin 1999; Micozzi 1999)

Estudos comprovam mais de 53 propriedades de NONI, dentre elas: regenerador celular, antiséptico natural, analgésico, antiinflamatório, antiparasitário, anticancerígeno, regenerador de células danificadas, regulador metabólico, entre outras. Essas propriedades devem-se a presença dos seguintes componentes ativos presentes no NONI: Xeronina, Damnacantal, Enzimas, Escopoletina, Bromelaina, Bioflavonóides.

O NONI estimula a produção de Óxido Nítrico, um gás produzido pelas células do nosso corpo, que tem como função: dilatação dos vasos sanguíneos, contribuindo assim para a normalização da pressão arterial, melhora da circulação e oxigenação, prevenindo a angina pectoris e a impotência sexual, e melhorando a memória; ajuda a combater os radicais livres e a evitar a oxidação do "mau" colesterol (LDL); inibe a coagulação prematura do sangue, prevenindo o bloqueio nas artérias, causadores de infartos cardíacos e cerebrais; estimula o sistema imunológico contra bactérias, vírus e células cancerígenas; melhora a eficiência da comunicação entre as células cerebrais e o resto do corpo; ajuda a manter os níveis de insulina no sangue, auxiliando no controle e prevenção do diabete; provê um estímulo adequado para a secreção do hormônio de crescimento, fator chave para evitar o envelhecimento e manutenção da massa muscular e da densidade óssea.

\section{Escopo}

O banco de dados Espacenet e o do INPI foram escolhidos para a realização do levantamento

Tabela de pesquisa por palavras-chave

\begin{tabular}{lcc}
\hline Palavra-chave & INPI & Espacenet \\
\hline morinda & 4 & 403 \\
citrifolia & 3 & 135 \\
citrifolia and morinda & 3 & 131 \\
Noni & 0 & 75 \\
\hline
\end{tabular}


de anterioridade, sendo que o primeiro oferece uma grande diversificação e acessibilidade mundial. No início a pesquisa encontrou 131 patentes pesquisados no banco de dados da Espacenet, com a palavra-chave citrifolia and morinda*, sendo para morinda encontrou-se 403 patentes, pesquisadas em Janeiro de 2009.

\section{Resultados e Discussão}

1. Evolução anual da publicação de patentes

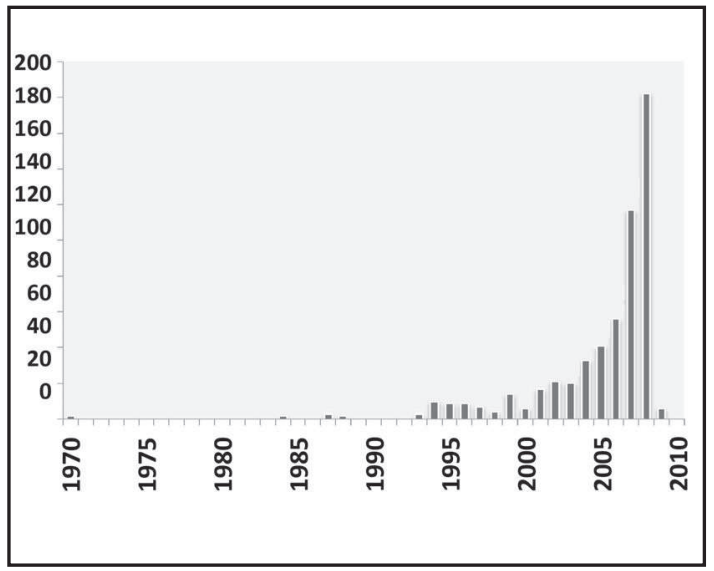

Como pode ser observado, houve um aumento significativo de patentes publicadas apartir do ano de 1995, elevando-se o seu valor nos últimos anos, talvez provocado pelo interesse comum em descobrir alternativas na área de medicamentos e aumento de pesquisas em instituições de pesquisas sobre o noni.

\section{Os dez inventores que mais patentearam}

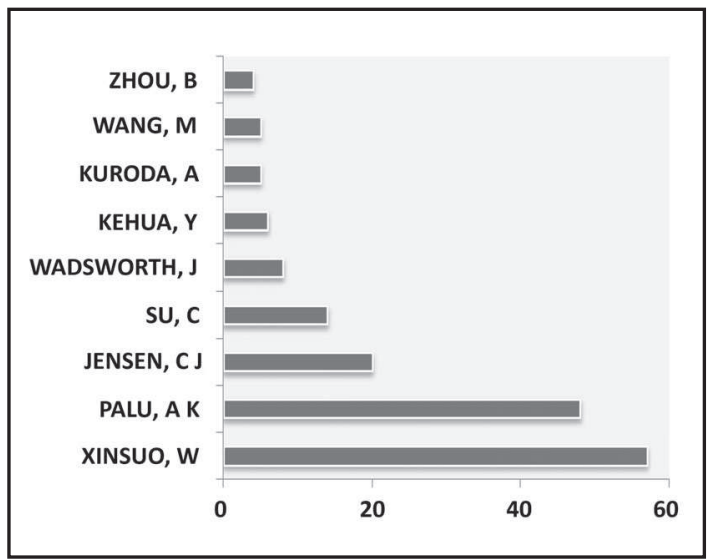

O presente gráfico demonstra os inventores que mais patentearam, evidenciando os pesquisadores da China com produção de 57 patentes.
3. Números de patentes publicadas e Número de inventores por país

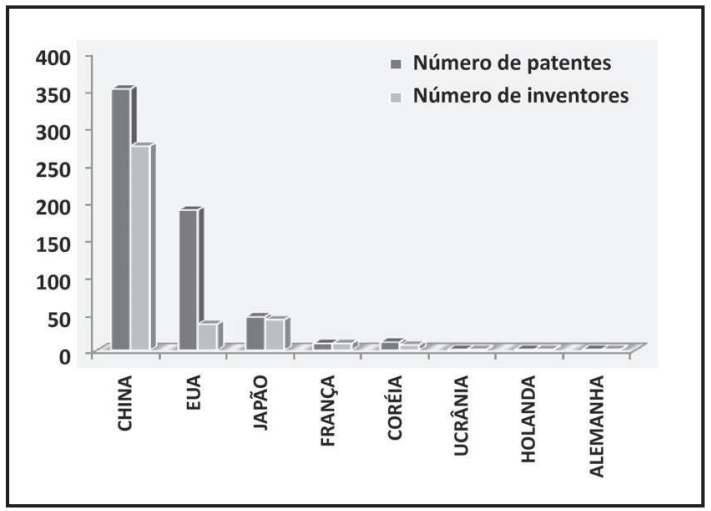

Nota-se no gráfico que a China se destaca com o maior número de patentes e inventores em relação aos demais.

4. Número de patentes por código internacional

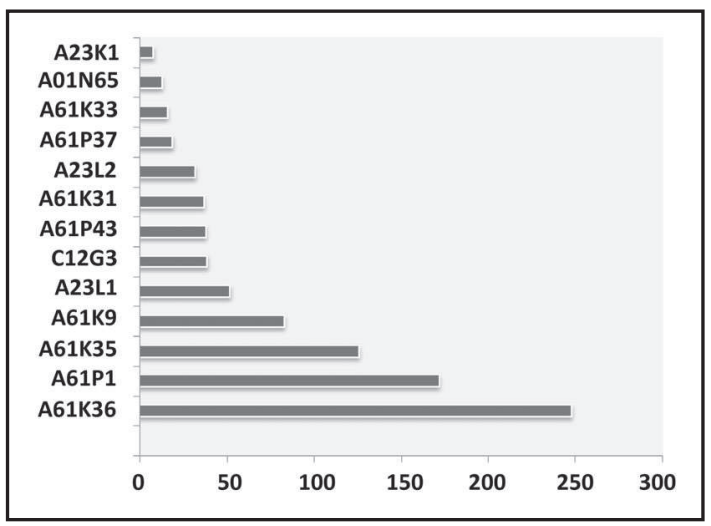

A61k36 - Caracterizados pelos ingredientes ativos ingredientes ativos orgânicos

A61P1 - Drogas para o tratamento de distúrbios do trato alimentar ou do sistema digestivo

A61k35 - Preparações medicinais contendo materiais de constituição indeterminada ou seus produtos de reação

A61k9 - Preparações medicinais caracterizadas por formas físicas especiais

A23L1 - Alimentos ou produtos alimentícios; sua preparação ou tratamento

C12g3 - Preparação de outras bebidas alcoólicas por fermentação direta, mistura como exemplo licores, com ingredientes aromatizantes.

A61P43 - Drogas para fins específicos, não previstos nos grupos de 1 - 41

A61k31 - Preparações medicinais contendo ingredientes ativos orgânicos

A23L2 - Bebidas não alcoólicas; composições secas para as mesmas; suas preparações

A61P37 - Drogas para o tratamento de distúrbios imunológicos ou alérgicos

A61k33 - Preparações medicinais contendo substâncias ativas inorgânicas 


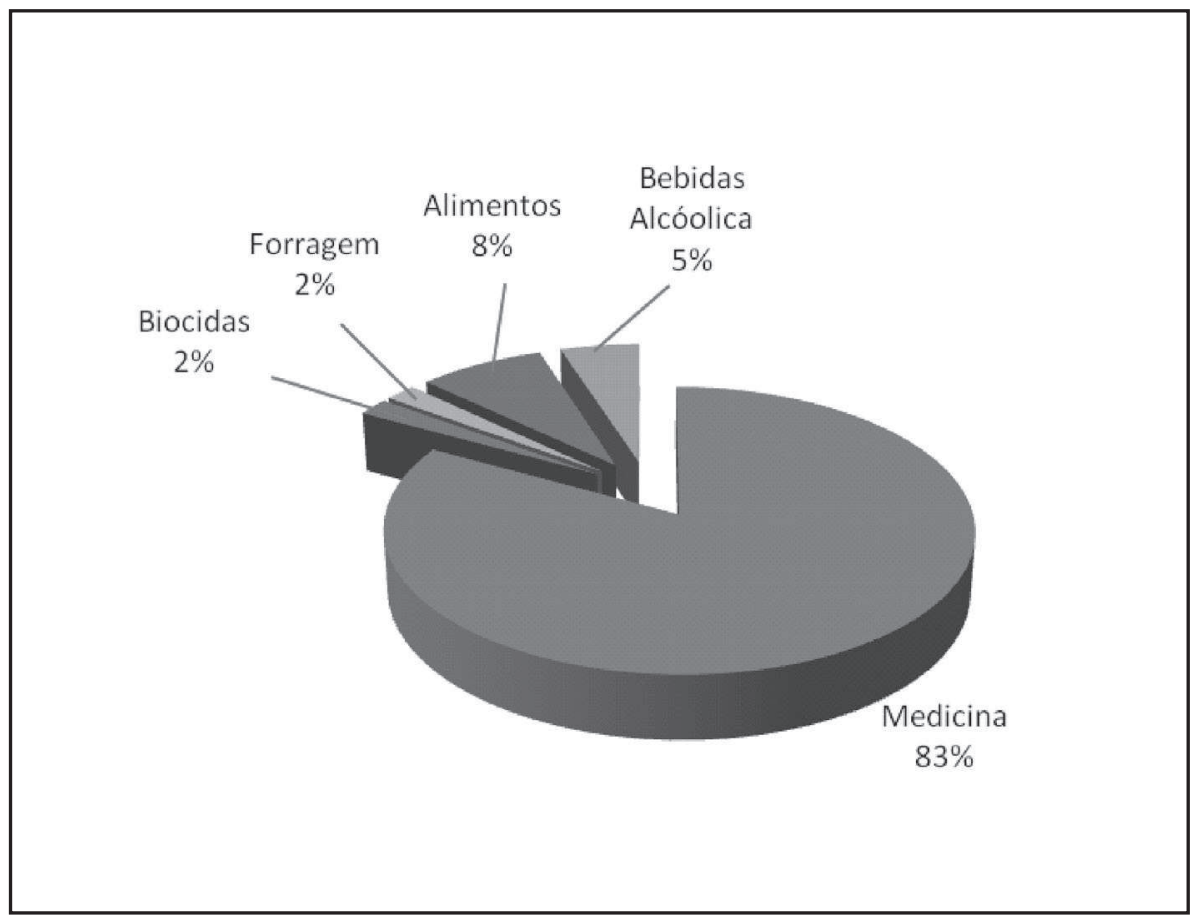

A01N65 - Biocidas, repelentes ou atrativos de pestes ou reguladores do crescimento de plantas, etc.

A23k1 - Forragem: produtos alimentícios para animais

Observa-se que há uma maior representatividade do código $\mathrm{A}$, indicando a utilização desse produto nas necessidades humanas, ressaltando uma presença maior de patentes no código $A 61 \mathrm{k} 36$, caracterizados pelos ingredientes ativos orgânicos.

A principal área de aplicação ocorre na medicina para tratamento de diversas doenças, como por exemplo as cancerígenas.

\section{Conclusões}

Os dados estatísticos revelam uma área promissora com crescimento relevante de patentes nos últimos 10 anos, ocorrendo principalmente no ano de 2008. As empresas estrangeiras são as que mais patenteiam nessa área, apesar do Brasil possuir um grande potencial, o que mostra uma lacuna a ser preenchida de modo promissor. Portanto, o número de patentes vem crescendo gradativamente, com o NONI sendo utilizado cada vez mais na medicina e como alimentos o que mostram os dados da presente pesquisa, já que mais de $70 \%$ das pesquisas são aplicadas a essas áreas. A China é o país que mais publica patentes referentes ao Morinda citrifolia.

\section{Referências}

Fontanarosa, Phil B., ed. 2000. Alternative Medicine:An Objective Assessment. American Medical Association. Chicago, IL.

Jonas, Wayne B and Jeffrey S. Levin. 1999. Essentials of Complementary and Alternative Medicine. Lippincott Williams and Wilkins. Philadelphia, PA.

Micozzi, Marc S., ed. 1999. Current Review of Complementary Medicine. Current Medicine, Inc. Philadelphia, PA.

http://ep.espacenet.com, acessado em 22/02/ 2009.

http: //www.inpi.gov.br/menu-esquerdo/patente. acessado em 20/11/2008.

Naylene Carvalho Sales da Silva é aluna de graduação em Ciências Agrárias da UFPI. Este trabalho foi realizado no semestre de 2008.2 durante a disciplina optativa "Marcas, Patentes e Propriedade Industrial" ministrada pela Prof ${ }^{a}$. Maria Rita M. S. Santos. Não tinha tido contato anterior com o tema. 